University of Wollongong

Research Online

Faculty of Engineering and Information

Faculty of Engineering and Information

Sciences - Papers: Part A

Sciences

$1-1-2014$

\title{
Numerical analysis of high-strength concrete-filled steel tubular slender beam-columns under cyclic loading
}

Vipulkumar Patel

Victoria University

Qing Quan Liang

Victoria University

Muhammad N. S Hadi

University of Wollongong, mhadi@uow.edu.au

Follow this and additional works at: https://ro.uow.edu.au/eispapers

Part of the Engineering Commons, and the Science and Technology Studies Commons

Research Online is the open access institutional repository for the University of Wollongong. For further information contact the UOW Library: research-pubs@uow.edu.au 


\title{
Numerical analysis of high-strength concrete-filled steel tubular slender beam- columns under cyclic loading
}

\begin{abstract}
The effects of cyclic local buckling on the behavior of concrete-filled steel tubular (CFST) slender beamcolumns under cyclic loading were approximately considered in existing analytical methods by modifying the stress- strain curve for the steel tube in compression. These methods, however, cannot simulate the progressive cyclic local buckling of the steel tubes. This paper presents a new efficient numerical model for predicting the cyclic performance of high strength rectangular CFST slender beam-columns accounting for the effects of progressive cyclic local buckling of steel tube walls under stress gradients. Uniaxial cyclic constitutive laws for the concrete core and steel tubes are incorporated in the fiber element formulation. The effects of initial geometric imperfections, high strength materials and second order are also included in the nonlinear analysis of CFST slender beam-columns under constant axial load and cyclically varying lateral loading. The Müller's method is adopted to solve nonlinear equilibrium equations. The accuracy of the numerical model is examined by comparisons of computer solutions with experimental results available in the published literature. A parametric study is conducted to investigate the effects of cyclic local buckling, columnslenderness ratio, depth-to-thickness ratio, concrete compressive strength and steel yield strength on the cyclic responses of CFST slender beamcolumns. It is shownthat the numerical model developed predicts well the experimentally observed cyclic lateral load-deflection characteristics of CFST slender beam-columns. The numerical results presented reflect the cyclic local and global buckling behavior of thin-walled high strength rectangular CFST slender beamcolumns, which have not been reported in the literature.
\end{abstract}

\section{Keywords}

high, strength, concrete, filled, analysis, steel, numerical, tubular, slender, beam, columns, under, cyclic, loading

\author{
Disciplines \\ Engineering | Science and Technology Studies
}

\section{Publication Details}

Patel, V. Ishvarbhai., Liang, Q. \& Hadi, M. N. S. (2014). Numerical analysis of high-strength concrete-filled steel tubular slender beam-columns under cyclic loading. Journal of Constructional Steel Research, 92 183-194. 


\title{
Journal of Constructional Steel Research
}

\author{
January 2013
}

\section{Numerical Analysis of High-Strength Concrete-Filled Steel Tubular Slender Beam-Columns under Cyclic Loading}

\author{
Vipulkumar Ishvarbhai Patel ${ }^{\mathrm{a}}$, Qing Quan Liang ${ }^{\mathrm{a}, *}$, Muhammad N. S. Hadi $^{\mathrm{b}}$ \\ ${ }^{a}$ College of Engineering and Science, Victoria University, PO Box 14428, Melbourne, \\ VIC 8001, Australia \\ ${ }^{\mathrm{b}}$ School of Civil, Mining and Environmental Engineering, University of Wollongong, \\ Wollongong, NSW 2522, Australia
}

\section{Corresponding author:}

Associate Professor Qing Quan Liang

College of Engineering and Science

Victoria University

PO Box 14428

Melbourne VIC 8001

Australia

Phone: +61 399194134

E-mail: Qing.Liang@vu.edu.au 


\title{
Numerical analysis of high-strength concrete-filled steel tubular slender beam-columns under cyclic loading
}

\author{
Vipulkumar Ishvarbhai Patel ${ }^{\mathrm{a}}$, Qing Quan Liang ${ }^{\mathrm{a}, *}$, Muhammad N. S. Hadi ${ }^{\mathrm{b}}$ \\ ${ }^{a}$ College of Engineering and Science, Victoria University, PO Box 14428, Melbourne, \\ VIC 8001, Australia \\ ${ }^{b}$ School of Civil, Mining and Environmental Engineering, University of Wollongong, \\ Wollongong, NSW 2522, Australia
}

\section{ABSTRACT}

The effects of cyclic local buckling on the behavior of concrete-filled steel tubular (CFST) slender beam-columns under cyclic loading were approximately considered in existing analytical models by modifying the stress-strain curve for the steel tube in compression. This modified stress-strain curve method, however, cannot simulate the progressive cyclic local and post-local buckling of the steel tubes. This paper presents a new efficient numerical model for predicting the cyclic performance of high strength thin-walled rectangular CFST slender beam-columns accounting for the effects of progressive cyclic local and post-local buckling of steel tube walls under stress gradients. Uniaxial cyclic constitutive laws for the concrete core and steel tubes are incorporated in the fiber element formulation of the model. The effects of initial geometric imperfections, high strength materials and second order are also included in the nonlinear analysis of CFST slender beam-columns under constant axial load and cyclically varying lateral loading. The Müller’s method is adopted to solve nonlinear equilibrium equations. The accuracy of the numerical model is examined by comparisons of

\footnotetext{
* Corresponding author. Tel.: 61399194134.

E-mail address: Qing.Liang@vu.edu.au (Q. Q. Liang)
} 
computer solutions with experimental results available in the published literature. A parametric study is conducted to investigate the effects of cyclic local buckling, column slenderness ratio, depth-to-thickness ratio, concrete compressive strength and steel yield strength on the cyclic responses of CFST slender beam-columns. It is shown that the numerical model developed predicts well the experimentally observed cyclic lateral loaddeflection characteristics of CFST slender beam-columns. The numerical results presented reflect the cyclic local and global buckling behavior of thin-walled high strength rectangular CFST slender beam-columns, which have not been reported in the literature.

Keywords: Concrete-filled steel tubes; Cyclic loading; High strength; Local and post-local buckling; Nonlinear analysis; Slender beam-columns.

\section{Introduction}

High strength thin-walled rectangular CFST slender beam-columns have increasingly been used in composite buildings and bridges in seismic regions due to their high structural performance such as high strength, high stiffness, high ductility and large energy absorption capacity. In seismic regions, thin-walled CFST slender beam-columns may be subjected to a constant axial load from upper floors and cyclically varying lateral loading due to the earthquake. These cyclically loaded beam-columns may undergo cyclic local and global interaction buckling, which makes the predictions of their cyclic performance highly complicated. Cyclic local buckling reduces the strength and ductility of thin-walled CFST slender beam-columns. It is therefore important to incorporate cyclic local buckling effects in nonlinear analysis techniques so that the cyclic performance of thin-walled CFST slender beam-columns under cyclic loading can be accurately predicted. 
Experimental studies on the ultimate strengths of CFST columns under monotonic axial load or combined monotonic axial load and bending have been very extensive in the past [1-12]. However, only limited tests have been conducted on CFST beam-columns under cyclic loading. Experiments on square CFST beam-columns under axial load and cyclic lateral loading were performed by Varma et al. $[13,14]$. These test specimens were made of high strength concrete of $110 \mathrm{MPa}$ and steel tube with yield stress ranging from $269 \mathrm{MPa}$ to 660 MPa. Their studies indicated that the cracking of the infilled concrete and local buckling of the steel tubes reduced the flexural stiffness of CFST beam-columns. Han et al. [15] investigated experimentally the effects of the depth-to-thickness ratio, concrete compressive strength and axial load level on the cyclic behavior of square and rectangular CFST beamcolumns. They reported that local buckling of CFST beam-columns occurred after the steel yielded. Tests on normal strength square CFST beam-columns under cyclic loading were undertaken by Wu et al. [16]. It was observed that the steel tube walls buckled outward after the concrete was damaged.

Various nonlinear analysis techniques for predicting the cyclic responses of CFST beamcolumns have been reported in the literature. Varma et al. [13] developed a fiber element model for rectangular CFST beam-columns under cyclic loading. The uniaxial cyclic stressstrain relationships for steel and concrete were derived from the nonlinear finite element analyses of CFST beam-columns. The stress-strain curve for steel in compression was modified to approximately account for the effects of local buckling. Gayathri et al. $[17,18]$ proposed an efficient fiber element technique for the nonlinear analysis of CFST short and slender beam-columns under monotonic and cyclic loading. Their technique was formulated for normal strength CFST beam-columns where local buckling effects were not included. Chung et al. [19] presented a fiber element model for the analysis of cyclically loaded square 
CFST beam-columns. The effect of local buckling was approximately taken into account in the model by modifying the stress-strain curve for steel in compression. However, their model did not consider concrete tensile strength and high strength materials. Zubydan and ElSabbagh [20] proposed a mathematical model for the nonlinear analysis of normal strength rectangular CFST beam-columns where local buckling was approximately considered by modifying the stress-strain curve for steel in compression. The fiber element model presented by $\mathrm{Wu}$ et al. [16] could be used to analyze normal strength square CFST beam-columns, providing that the steel sections are compact. It should be noted that the modified stress-strain curve method used in the above mentioned models might overestimate or underestimate the cyclic local buckling strengths of steel tubes under stress gradients. This is because they can not model the progressive cyclic local buckling of the steel tube from the onset to the postlocal buckling, which is characterized by stress redistributions within the buckled tube wall.

The local buckling problem of thin-walled CFST columns has been studied experimentally by various researchers [21-24]. Liang et al. [25] proposed a fiber element model for the nonlinear analysis of thin-walled CFST short columns under axial compression, accounting for progressive local buckling effects by using effective width formulas. Liang [26,27] developed a numerical model for simulating the axial load-strain responses, moment-curvature relationships and axial load-moment interaction diagrams of high strength rectangular CFST short beam-columns under axial load and biaxial bending. The effects of local buckling of steel tube walls under stress gradients were incorporated in the model by using initial local buckling equations and effective width formulas proposed by Liang et al [28]. Patel et al.[29,30] and Liang et al. [31] extended the numerical models developed by Liang et al. [25] and Liang $[26,27]$ to the nonlinear analysis of eccentrically loaded high strength thin-walled 
rectangular CFST slender beam-columns considering the effects of local buckling, geometric imperfections, second order and high strength materials.

The above literature review indicates that there is relatively little numerical study on the fundamental behavior of cyclically loaded high strength rectangular CFST slender beamcolumns with large depth-to-thickness ratios. In this paper, a numerical model is developed to simulate the cyclic performance of high strength thin-walled rectangular CFST slender beamcolumns incorporating cyclic local buckling effects. Comparative study is undertaken to verify the numerical model. The fundamental cyclic behavior of CFST slender beam-columns under constant axial load and cyclically varying lateral loading is investigated using the computer program developed and the results obtained are discussed.

\section{Material constitutive models}

\subsection{Cyclic constitutive models for concrete}

The confinement provided by the steel tube increases only the ductility of the concrete core in a rectangular CFST column but not its strength. This confinement effect is considered in the cyclic stress-strain curves schematically depicted in Fig. 1. The cyclic stress-strain relationships account for the effects of stiffness degradation and crack opening and closing characteristics of concrete under cyclic loading. The envelope curve for the concrete under cyclic axial compression can be characterized by the monotonic stress-strain curve of the concrete, which is divided into ascending, constant, linearly descending and constant parts as shown in Fig. 1. The longitudinal compressive concrete stress for the ascending part from $\mathrm{O}$ to $\mathrm{A}$ is calculated based on the equation given by Mander et al. [32] as: 


$$
\begin{gathered}
\sigma_{c}=\frac{f_{c c}^{\prime} \lambda\left(\frac{\varepsilon_{c}}{\varepsilon_{c c}^{\prime}}\right)^{\lambda}}{\lambda-1+\left(\frac{\varepsilon_{c}}{\varepsilon_{c c}^{\prime}}\right)^{\lambda}} \\
\lambda=\frac{E_{c}}{E_{c}-\left(\frac{f_{c c}^{\prime}}{\varepsilon_{c c}^{\prime}}\right)}
\end{gathered}
$$

where $f_{c c}^{\prime}$ is the effective compressive strength of concrete, $\varepsilon_{c}$ is the longitudinal compressive strain of concrete, $\varepsilon_{c c}^{\prime}$ is the strain at $f_{c c}^{\prime}$ and $E_{c}$ is the Young's modulus of concrete which is given by ACI 318-11 [33] as

$$
E_{c}=3320 \sqrt{f_{c c}^{\prime}}+6900 \quad(\mathrm{MPa})
$$

The effective compressive strengths of concrete $\left(f_{c c}^{\prime}\right)$ is taken as $\lambda_{c} f_{c}^{\prime}$, where $\lambda_{c}$ is the strength reduction factor proposed by Liang [26] to account for the column size effects and expressed as

$$
\lambda_{c}=1.85 D_{c}^{-0.135} \quad\left(0.85 \leq \lambda_{c} \leq 1.0\right)
$$

in which $D_{c}$ is taken as the larger of $(B-2 t)$ and $(D-2 t)$ for a rectangular cross-section, where $B$ is the width of the cross-section, $D$ is the depth of the cross-section, and $t$ is the thickness of the steel tube wall.

In the numerical model, the strain $\varepsilon_{c c}^{\prime}$ corresponding to $f_{c c}^{\prime}$ is taken as 0.002 for the effective 
compressive strength less than or equal to $28 \mathrm{MPa}$ and 0.003 for $f_{c c}^{\prime}>82 \mathrm{MPa}$. For the effective compressive strength between 28 and $82 \mathrm{MPa}$, the strain $\varepsilon_{c c}^{\prime}$ is determined by the linear interpolation.

The parts $A B, B C$ and $C D$ of the stress-strain curve for concrete in CFST columns as shown in Fig. 1 are defined by the following equations given by Liang [26]:

$\sigma_{c}= \begin{cases}f_{c c}^{\prime} & \text { for } \varepsilon_{c c}^{\prime}<\varepsilon_{c} \leq 0.005 \\ \beta_{c} f_{c c}^{\prime}+100\left(0.015-\varepsilon_{c}\right)\left(f_{c c}^{\prime}-\beta_{c} f_{c c}^{\prime}\right) & \text { for } 0.005<\varepsilon_{c} \leq 0.015 \\ \beta_{c} f_{c c}^{\prime} & \text { for } \varepsilon_{c}>0.015\end{cases}$

where $\beta_{c}$ was proposed by Liang [26] based on experimental results presented by Tomii and Sakino [34] as follows:

$\beta_{c}= \begin{cases}1.0 & \text { for } \frac{B_{s}}{t} \leq 24 \\ 1.5-\frac{1}{48} \frac{B_{s}}{t} & \text { for } 24<\frac{B_{s}}{t} \leq 48 \\ 0.5 & \text { for } \frac{B_{s}}{t}>48\end{cases}$

in which $B_{s}$ is taken as the larger of $B$ and $D$ for a rectangular cross-section.

The concrete under compression is initially loaded up to an unloading strain and then unloaded to a zero stress level. The reloading of the concrete from the zero stress up to the envelope curve is characterized by the linear stress-strain relationships. For the unloading of concrete, the parabolic curve of the concrete is defined by the following equations [32]: 


$$
\begin{aligned}
& \sigma_{c}=f_{u n}-\frac{f_{u n} \lambda_{u}\left(\frac{\varepsilon_{c}-\varepsilon_{u n}}{\varepsilon_{p l}-\varepsilon_{u n}}\right)}{\lambda_{u}-1+\left(\frac{\varepsilon_{c}-\varepsilon_{u n}}{\varepsilon_{p l}-\varepsilon_{u n}}\right)^{\lambda_{u}}} \quad\left(\varepsilon_{p l}<\varepsilon_{c}<\varepsilon_{u n}\right) \\
& \lambda_{u}=\frac{E_{u}}{E_{u}-\left(\frac{f_{u n}}{\varepsilon_{u n}-\varepsilon_{p l}}\right)}
\end{aligned}
$$

where $f_{u n}$ is the compressive stress of concrete at the unloading, $\varepsilon_{u n}$ is the strain at $f_{u n}, \varepsilon_{p l}$ is the plastic strain which is proposed by Mander et al. [32] as:

$\varepsilon_{p l}=\varepsilon_{u n}-\frac{f_{u n} \varepsilon_{u n}+f_{u n} \varepsilon_{a}}{f_{u n}+E_{c} \varepsilon_{a}}$

in which $\varepsilon_{a}$ is given as

$\varepsilon_{a}=a \sqrt{\varepsilon_{u n} \varepsilon_{c c}^{\prime}}$

where $a$ is taken as the larger of $\varepsilon_{c c}^{\prime} /\left(\varepsilon_{c c}^{\prime}+\varepsilon_{u n}\right)$ and $0.09 \varepsilon_{u n} / \varepsilon_{c c}$ for a rectangular crosssection.

In Eq. (8), $E_{u}$ is the initial modulus of elasticity at the unloading proposed by Mander et al. [32] and is expressed by:

$$
E_{u}=\left(\frac{f_{u n}}{f_{c c}^{\prime}}\right)\left(\sqrt{\frac{\varepsilon_{c c}^{\prime}}{\varepsilon_{u n}}}\right) E_{c}
$$


in which $\left(f_{u n} / f_{c c}^{\prime}\right) \geq 1.0$, and $\sqrt{\varepsilon_{c c}^{\prime} / \varepsilon_{u n}} \leq 1.0$.

For the reloading of concrete, a linear stress-strain relationship is assumed as follows:

$$
\sigma_{c}=E_{r}\left(\varepsilon_{c}-\varepsilon_{r o}\right)+f_{r o} \quad\left(\varepsilon_{p l}<\varepsilon_{c}<\varepsilon_{r o}\right)
$$

where $E_{r}$ is given by

$$
E_{r}=\frac{f_{r o}-f_{r e}}{\varepsilon_{r o}-\varepsilon_{r e}}
$$

in which $f_{r o}$ is the concrete stress at the reloading, $\varepsilon_{r o}$ is the strain at $f_{r o}$, and $\varepsilon_{r e}$ and $f_{r e}$ are the return strain and stress on the monotonic curve as shown in Fig. 1.

The envelop stress-strain curve for concrete under tension is divided into the linear descending and ascending parts as shown in Fig. 1. The concrete tensile stress linearly increases with the tensile strain of concrete up to concrete cracking. After concrete cracking, the tensile stress of concrete is inversely proportional to the tensile strain of concrete up to the ultimate tensile strain. The tensile strength of concrete is taken as $0.6 \sqrt{f_{c c}^{\prime}}$. The concrete tensile stress is considered zero at the ultimate tensile strain. The ultimate tensile strain is taken as 10 times of the strain at cracking.

For unloading from a compressive envelope curve, the stress in the concrete fiber under tension can be given by: 
$\sigma_{t}= \begin{cases}\frac{f_{c t}^{\prime}\left(\varepsilon_{c}-\varepsilon_{p l}\right)}{\left(\varepsilon_{c t}^{\prime}-\varepsilon_{t u}^{\prime}\right)} & \text { for } \varepsilon_{t u}^{\prime}<\varepsilon_{c} \leq \varepsilon_{c t}^{\prime} \\ \frac{f_{c t}^{\prime}\left(\varepsilon_{c}-\varepsilon_{p l}\right)}{\varepsilon_{c t}^{\prime}} & \text { for } \varepsilon_{c t}^{\prime}<\varepsilon_{c}<\varepsilon_{p l}\end{cases}$

in which

$$
\begin{aligned}
& f_{c t}^{\prime}=f_{c t}\left(1-\frac{\varepsilon_{p l}}{\varepsilon_{c c}^{\prime}}\right) \\
& \varepsilon_{c t}^{\prime}=\varepsilon_{c t}+\varepsilon_{p l}
\end{aligned}
$$

For unloading from a tensile envelope curve, the reloading the concrete cannot carry the load up to the tensile strength so that the reloading branch follows the unloading branch.

\subsection{Cyclic constitutive models for structural steels}

The cyclic stress-strain relationship for the structural steels is shown in Fig. 2. The mild structural steels have a linear stress-strain relationship up to $0.9 f_{s y}$, where $f_{s y}$ is the steel yield strength. The parabolic curve for cold-formed structural steels can be defined by the equation proposed by Liang [26]. The parabolic curve is replaced by the straight line for high strength steels. The hardening strain $\varepsilon_{\text {st }}$ is assumed to be 0.005 for high strength and coldformed steels and $10 \varepsilon_{s y}$ for mild structural steels in the numerical model. The ultimate strain of steels is taken as 0.2 .

For the cyclic stress-strain curve, the unloading follows a straight line with the same slope as 
the initial stiffness as shown in Fig. 2. The unloading part of the structural steels can be defined by the following equation:

$$
\sigma_{s}=E_{s}\left(\varepsilon_{s}-\varepsilon_{m o}\right) \quad\left(\varepsilon_{o}<\varepsilon_{s} \leq \varepsilon_{m o}\right)
$$

where $\sigma_{s}$ is the stress in a steel fiber, $E_{s}$ is the Young's modulus of steel, $\varepsilon_{s}$ is the strain in the steel fiber and $\varepsilon_{m o}$ is given by:

$$
\varepsilon_{m o}=\varepsilon_{o}-\frac{f_{o}}{E_{s}}
$$

in which $\varepsilon_{o}$ is the strain at the unloading, $f_{o}$ is the stress at the unloading.

The reloading curve for steels is described by the equations given by Shi et al. [35] as:

$$
\begin{array}{ll}
\sigma_{s}=E_{s}\left(\varepsilon_{s}-\varepsilon_{m o}\right)-\eta\left(E_{s}-E_{k}\right)\left(\varepsilon_{s}-\varepsilon_{o}\right) & \left(\varepsilon_{m o}<\varepsilon_{s} \leq \varepsilon_{b}\right) \\
E_{k}=\frac{\sigma_{b}}{\varepsilon_{b}-\varepsilon_{m o}} &
\end{array}
$$

where $\eta$ is proposed by Shi et al. [35] as:

$$
\eta=\left\{\begin{array}{cc}
1.048-\frac{0.05}{\frac{\varepsilon_{s}-\varepsilon_{o}}{\varepsilon_{b}-\varepsilon_{o}}+0.05} & \text { for }\left|\varepsilon_{b}-\varepsilon_{o}\right| \geq 0.04 \\
1.074-\frac{0.08}{\frac{\varepsilon_{s}-\varepsilon_{o}}{\varepsilon_{b}-\varepsilon_{o}}+0.08} & \text { for }\left|\varepsilon_{\mathrm{b}}-\varepsilon_{o}\right|<0.04
\end{array}\right.
$$


For the reloading, the initial value of the strain $\varepsilon_{b}$ is taken as $0.9 \varepsilon_{s y}$. The stress $f_{b}$ at the strain $\varepsilon_{b}$ can be determined from the monotonic stress-strain curves. For the strain greater than the strain $\varepsilon_{b}$, the cyclic skeleton curve is used to predict the stress in the steel fiber. After initial reloading, the reloading is directed toward the previous unloading.

\section{Modeling of cross-sectional strengths}

\subsection{Strain calculations}

The behavior of composite cross-sections is modeled using the accurate fiber element method. The cross-section is divided into fiber elements as shown in Fig. 3. Each fiber element can be assigned with either steel or concrete material properties. Fiber element stresses are calculated from fiber strains using cyclic stress-strain relationships. The strain $\varepsilon_{t}$ at the top fiber of the cross-section can be determined by multiplication of the curvature $\phi$ and the neutral axis depth $d_{n}$. For bending about the $x$-axis, strains in concrete and steel fibers can be calculated by the following equations proposed by Liang [26]:

$$
\begin{aligned}
& y_{n, i}=\frac{D}{2}-d_{n} \\
& d_{e, i}=\left|y_{i}-y_{n, i}\right| \\
& \varepsilon_{i}= \begin{cases}\phi d_{e, i} & \text { for } y_{i} \geq y_{n, i} \\
-\phi d_{e, i} & \text { for } y_{i}<y_{n, i}\end{cases}
\end{aligned}
$$

in which $d_{n}$ is the neutral axis depth, $d_{e, i}$ is the orthogonal distance from the centroid of each 
fiber element to the neutral axis, $y_{i}$ is the coordinates of the fiber $i$ and $\varepsilon_{i}$ is the strain at the ith fiber element.

\subsection{Initial local buckling of steel tube walls under stress gradients}

The steel tube walls of a CFST column are restrained by the concrete core so that they can only buckle outward. The edges of the tube wall can be assumed as clamped. Liang et al. [28] developed nonlinear finite element models to study the local and post-local buckling behavior of clamped steel plates that form a CFST column under stress gradients. The models accounted for geometric imperfection of $0.1 t$ at the plate centre and compressive residual stresses of $0.25 f_{s y}$, which were balanced by the tensile residual stresses locked in the same plate. Based on the finite element results, Liang et al. [28] proposed a set of formulas for determining the initial local buckling stress of steel tube walls subjected to compressive stress gradients. These formulas are incorporated in the numerical model to determine the onset of cyclic local buckling of thin-walled CFST slender beam-columns.

\subsection{Post-local buckling of steel tube walls under stress gradients}

The effective width concept is usually used to determine the post-local buckling strengths of thin steel plates. Liang et al. [28] proposed a set of effective width formulas for steel tube walls of CFST columns under compressive stress gradients. The effective width is a function of the width-to-thickness ratio $(b / t)$ and compressive stress gradient $\left(\alpha_{s}\right)$. Their formulas are incorporated in the numerical model to determine the ultimate strengths of steel tube walls subjected to stress gradients. Fig. 3 shows the effective and ineffective areas of a steel cross- 
section under axial load and uniaxial bending. The effective widths $b_{e 1}$ and $b_{e 2}$ of a steel tube wall under stress gradients are given by Liang et al. [28] as

$$
\begin{aligned}
& \frac{b_{e 1}}{b}=\left\{\begin{array}{l}
0.2777+0.01019\left(\frac{b}{t}\right)-1.972 \times 10^{-4}\left(\frac{b}{t}\right)^{2}+9.605 \times 10^{-7}\left(\frac{b}{t}\right)^{3} \text { for } \alpha_{\mathrm{s}}>0.0 \\
0.4186-0.002047\left(\frac{b}{t}\right)+5.355 \times 10^{-5}\left(\frac{b}{t}\right)^{2}-4.685 \times 10^{-7}\left(\frac{b}{t}\right)^{3} \text { for } \alpha_{\mathrm{s}}=0
\end{array}\right. \\
& \frac{b_{e 2}}{b}=\left(2-\alpha_{s}\right) \frac{b_{e 1}}{b}
\end{aligned}
$$

where $b$ is the clear width of a steel flange or web in the section, and $\alpha_{s}=\sigma_{2} / \sigma_{1}, \sigma_{1}$ is the maximum edge stress acting on the steel tube wall and $\sigma_{2}$ is the minimum edge stress acting on the same steel tube wall. It is noted that the effective width formulas were proposed for clamped steel plates with $b / t$ ratio ranging from 30 to 100 . For a plate with a $b / t$ ratio less than 30 , the plate is treated as compact.

The post-local buckling of a thin steel plate is characterized by the gradual redistribution of stresses within the buckled plate. After the onset of local buckling, the ineffective width of the plate increases with increasing the compressive load until the plate attains its ultimate strength, which is governed by the effective widths given by Eqs. (25) and (26). In the present study, the progressive post-local buckling of steel tube walls under stress gradients is modeled by gradually redistributing the normal stresses within the steel tube wall. This can be done by assigning the steel fiber elements located in the ineffective areas to zero stress (Liang 26).

\subsection{Stress resultants}


The internal axial force and bending moment carried by a composite cross-section under axial load and uniaxial bending are determined as the stress resultants, which are expressed by:

$$
\begin{aligned}
& P_{n}=\sum_{i=1}^{n s} \sigma_{s, i} A_{s, i}+\sum_{j=1}^{n c} \sigma_{c, j} A_{c, j} \\
& M_{x}=\sum_{i=1}^{n s} \sigma_{s, i} A_{s, i} y_{i}+\sum_{j=1}^{n c} \sigma_{c, j} A_{c, j} y_{j}
\end{aligned}
$$

where $P_{n}$ is the internal axial force, $M_{x}$ is the internal bending moment about the $x$-axis, $\sigma_{s, i}$ is the longitudinal stress at the centroid of steel fiber $i, A_{s, i}$ is the area of steel fiber $i, \sigma_{c, j}$ is the longitudinal stress at the centroid of concrete fiber $j, A_{c, j}$ is the area of concrete fiber $j$, $y_{i}$ is the coordinates of steel element $i, y_{j}$ is the coordinates of concrete element $j, n s$ is the total number of steel fiber elements and $n c$ is the total number of concrete fiber elements.

\subsection{The Müller's method}

The Müller's method [36] is an efficient numerical technique for solving nonlinear equilibrium equations. It is a generalization of the secant method, which has been used to obtain nonlinear solutions to CFST short beam-columns under axial load and biaxial bending by Liang [26]. Computational algorithms based on the Müller's method are developed to iterate the neutral axis depth in a rectangular CFST cross-section. The Müller's method requires three initial values of the neutral axis depth $d_{n, 1}, d_{n, 2}$ and $d_{n, 3}$. The corresponding residual forces $r_{p, 1}, r_{p, 2}$ and $r_{p, 3}$ are calculated based on the three initial values of the neutral axis depth. The new neutral axis depth $d_{n, 4}$ is determined by the following equations: 


$$
\begin{aligned}
& d_{n, 4}=d_{n, 3}-\frac{2 c_{m}}{b_{m} \pm \sqrt{b_{m}^{2}-4 a_{m} c_{m}}} \\
& a_{m}=\frac{\left(d_{n, 2}-d_{n, 3}\right)\left(r_{p, 1}-r_{p, 3}\right)-\left(d_{n, 1}-d_{n, 3}\right)\left(r_{p, 2}-r_{p, 3}\right)}{\left(d_{n, 1}-d_{n, 2}\right)\left(d_{n, 2}-d_{n, 3}\right)\left(d_{n, 1}-d_{n, 3}\right)} \\
& b_{m}=\frac{\left(d_{n, 1}-d_{n, 3}\right)^{2}\left(r_{p, 2}-r_{p, 3}\right)-\left(d_{n, 2}-d_{n, 3}\right)^{2}\left(r_{p, 1}-r_{p, 3}\right)}{\left(d_{n, 1}-d_{n, 2}\right)\left(d_{n, 2}-d_{n, 3}\right)\left(d_{n, 1}-d_{n, 3}\right)} \\
& c_{m}=r_{p, 3}
\end{aligned}
$$

The values of the neutral axis depth $d_{n, 1}, d_{n, 2}$ and $d_{n, 3}$ and corresponding residual forces $r_{p, 1}$, $r_{p, 2}$ and $r_{p, 3}$ need to be exchanged as discussed by Patel et al. [29]. Eq. (29) and the exchange of the neutral axis depths and residual forces are iteratively executed until the convergence criteria of $\left|r_{p}\right|<\varepsilon_{k}$ is satisfied. The sign of the square toot term in the denominator of Eq. (29) is taken as the same sign of $b_{m}$.

\section{Modeling of cyclic load-deflection responses}

\subsection{Formulation}

A cantilever column under a constant axial load $(P)$ and cyclically varying lateral loading $(F)$ is considered in the numerical model. The deflected shape and coordinate system for the cantilever column are depicted in Fig. 4, where $L$ represents the actual length of the column and $u_{l}$ demotes the lateral deflection at the tip of the column. The effective length of the cantilever column is taken as $2 L$. The deflected shape of the cantilever column is assumed to be part of a sine wave which is described by the following displacement function: 
$u=u_{l} \sin \left(\frac{\pi \mathrm{z}}{2 L}\right)$

The curvature along the length of the cantilever column can be derived from Eq. (33) as

$\phi=\frac{\partial^{2} u}{\partial z^{2}}=\left(\frac{\pi}{2 L}\right)^{2} u_{l} \sin \left(\frac{\pi \mathrm{z}}{2 L}\right)$

The curvature at the base of the cantilever column is given by

$\phi_{b}=\left(\frac{\pi}{2 L}\right)^{2} u_{l}$

The external moment at the base of the cantilever column can be determined as

$M_{m e}=F L+P\left(e+u_{l}+u_{l o}\right)$

in which $e$ is the eccentricity of the axial load and it is taken as zero for the pure axial load in the present study, $u_{l o}$ is the initial geometric imperfection at the tip of the cantilever columns.

The column must satisfy the force and moment equilibrium conditions at its base as follows:

$$
\begin{aligned}
& P_{n}-P=0 \\
& F L+P\left(e+u_{l}+u_{l o}\right)-M_{x}=0
\end{aligned}
$$


where $M_{x}$ is the internal bending moment of the cross-section at the column base.

The lateral load can be determined as:

$$
F=\frac{M_{x}-P\left(e+u_{l}+u_{l o}\right)}{L}
$$

\subsection{Computational procedure}

An incremental-iterative numerical scheme based on the displacement control method was employed in the computational procedure to predict the cyclic load-deflection responses of slender beam-columns. The lateral deflection at the tip of the beam-column is initialized. The curvature $\phi_{b}$ at the column base is calculated from the given lateral deflection $u_{l}$ using Eq. (35). The neutral axis depth of the composite cross-section is iteratively adjusted using the Müller's method. The force and moment equilibriums are maintained at the base of the cantilever column. The internal bending moment $M_{x}$ is determined from axial force and curvature relationship. The cyclic lateral load $F$ at the tip of the cantilever column is calculated using Eq. (39). The lateral deflection at the tip of the cantilever column is gradually increased up to the predefined unloading deflection. After the unloading deflection, the lateral deflection is gradually decreased up to the reloading level. Note that the stresses of the steel and concrete fiber elements depend not only on the strain of the element, but also on the complete stress-strain history. The stresses and strains of the fiber elements for each lateral deflection are recorded in the numerical analysis. The process is repeated until the ultimate cyclic lateral load is obtained or the deflection limit is reached. The main steps of the computational procedure are given as follows: 
(1) Input data.

(2) Discretize the composite cross-section into fiber elements.

(3) Initialize the first unloading deflection $u_{u l}$

(4) Initialize the lateral deflection at the tip of the cantilever column $u_{l}=\Delta u_{l}$.

(5) Calculate the curvature $\phi_{b}$ at the base of the cantilever column.

(6) Set $\Delta u_{l}=-\Delta u_{l}$ if $u_{l}>\left(u_{u l}-\Delta u_{l}\right)$ or $u_{l}<\left(-u_{u l}-\Delta u_{l}\right)$.

(7) Define the next unloading deflection $u_{u l}$ if $\left(u_{l}-u_{\text {llast }}\right)\left(u_{\text {llast }}-u_{\text {lold }}\right)<0$ and $u_{l}>u_{\text {llast }}$.

(8) Recall the unloading strains and stresses at the unloading deflection.

(9) Adjust the neutral axis depth $\left(d_{n}\right)$ using the Müller's method.

(10) Calculate fiber strains and stresses using cyclic stress-strain relationships.

(11) Check cyclic local buckling and update steel fiber stresses.

(12) Calculate resultant force $P$ considering local buckling effects.

(13) Compute the residual force $r_{p}=P_{n}-P$.

(14) Repeat Steps (9)-(13) until $\left|r_{p}\right|<\varepsilon_{k}$.

(15) Compute the internal bending moment $M_{x}$.

(16) Calculate the cyclic lateral force $F$ using Eq. (39).

(17) Record the deflection $u_{\text {lold }}=u_{\text {llast }}$ and $u_{\text {llast }}=u_{l}$

(18) Store the fiber strains and fiber stresses under the current deflection.

(19) Increase the deflection at the tip of the cantilever column by $u_{l}=u_{l}+\Delta u_{l}$.

(20) Repeat Steps (5)-(19) until the ultimate cyclic lateral load $F_{u}$ is obtained or the deflection limit is reached.

(21) Plot the cyclic load-deflection curve. 
The convergence tolerance $\varepsilon_{k}$ is taken as $10^{-4}$ in the numerical analysis.

\section{Validation of the numerical model}

The accuracy of the developed numerical model is evaluated by comparing the numerical solutions with experimental results given by Verma et al. [14]. The ultimate cyclic lateral loads and cyclic load-deflection curves for high strength thin-walled square CFST beamcolumns are considered in the verification of the numerical model developed.

\subsection{Ultimate cyclic lateral loads}

The dimensions and material properties of high strength CFST beam-columns tested by Varma et al. [14] are given in Table 1 . In the table, $F_{u \text {.exp }}$ represents the experimental ultimate cyclic lateral load and $F_{u \text { num }}$ denotes the ultimate cyclic lateral load predicted by the numerical model. Specimens were tested under rotating axial load and cyclic loading using special clevises-pins supports. All specimens had a square cross-section of $305 \times 305 \mathrm{~mm}$. The depth-to-thickness ratios $(D / t)$ ranged from 34 to 52 while the length of the column was $1200 \mathrm{~mm}$. The steel tube of the specimens was filled with high strength concrete of $110 \mathrm{MPa}$. It should be noted that the concrete compressive strength given in Table 1 is the cylinder

compressive strength. The yield strengths $\left(f_{s y}\right)$ of the steel tube varied from $269 \mathrm{MPa}$ to 660 MPa. The experimental axial load applied to each specimen was employed in the numerical analysis. It can be observed from Table 1 that the ultimate cyclic lateral loads predicted by the numerical model are in good agreement with experimental results. The mean ultimate cyclic 
lateral load predicted by the numerical model is $99 \%$ of the experimental value with a standard deviation of 0.11 and a coefficient of variation of 0.11 .

\subsection{Cyclic load-deflection curves}

Cyclic load-deflection curves provide useful information on the initial stiffness, ultimate cyclic lateral load, unloading stiffness, reloading stiffness and post-peak behavior of thinwalled CFST beam-columns. To examine the accuracy of the proposed numerical model, cyclic load-deflection curves predicted by the numerical model are compared with experimental results reported by Varma et al. [14] in Figs. 5-7.

The $D / t$ ratios of these columns ranged from 34 to 52 . Therefore, the local buckling of the steel tube wall under stress gradients was considered in the numerical model. It can be seen from Figs. 5-7 that the numerical model predicts well the ultimate cyclic lateral loads when compared to test results. The predicted ultimate cyclic lateral load for specimen CBC-32-8010 is $95 \%$ of the experimental value. Reasonable agreement between computed and experimental cyclic load-deflection curves is achieved for specimens CBC-48-80-10, CBC48-80-20, CBC-32-46-20, CBC-48-46-10 and CBC-48-46-20. The ratios of computed ultimate cyclic lateral load to experimental value for specimens CBC-48-80-10, CBC-48-8020, CBC-32-46-20, CBC-48-46-10 and CBC-48-46-20 are 1.14, 1.06, 0.86, 1.07 and 1.07, respectively. The predicted post-peak behavior of the cyclic load-deflection curves for specimens is in reasonable agreement with experimental data. The unloading and reloading stiffness of the cyclic load-deflection curves predicted by the numerical model slightly differ from experimental ones. This is likely due to the uncertainty of the actual concrete stiffness and strength. 


\section{Parametric study}

In the parametric study, the axial load was taken as $10 \%$ of the ultimate axial strength of the column cross-section. The computer program developed by Liang et al. [25] was used to determine the ultimate axial strengths of column cross-sections under axial compression. In the present study, the initial geometric imperfection at the tip of the beam-column was taken as $L / 1000$. The Young's modulus of steel material was $200 \mathrm{GPa}$. The yield stress of $690 \mathrm{MPa}$ and the tensile strength of $790 \mathrm{MPa}$ were assumed for steel tubes, except where specially indicated. The effects of cyclic local and post-local buckling were considered in all analyses. The typical cyclic loading pattern used in the parametric study is illustrated in Fig. 8.

\subsection{Effects of local buckling}

The numerical model was employed to investigate the effects of cyclic local buckling on the cyclic load-deflection curves for high strength CFST slender beam-columns under constant axial load and cyclically varying lateral loading. A thin-walled CFST beam-column with a cross-sectional dimension of $700 \times 800 \mathrm{~mm}$ was considered. The thickness of the steel tube was $8 \mathrm{~mm}$ so that its depth-to-thickness ratio $(D / t)$ was 100 . The compressive cylinder strength of concrete was $80 \mathrm{MPa}$. The column slenderness ratio $\left(L_{e} / r\right)$ was 22. The applied axial load was $4623.1 \mathrm{kN}$. Analyses of the beam-column were carried out by considering and ignoring cyclic local buckling effects respectively.

Fig. 9 shows the effects of cyclic local buckling on the cyclic load-deflection curves for thinwalled CFST beam-columns. It can be seen from Fig. 9 that cyclic local buckling considerably reduces the stiffness and ultimate cyclic lateral load of the slender beam-column 
with the same axial load level. The ultimate cyclic lateral load of the slender beam-column is overestimated by $4.3 \%$ if local buckling was not considered. More reduction in the ultimate cyclic lateral load would be expected if higher axial load was applied to the column. In addition, cyclic local buckling tends to reduce the ductility of the column under cyclic loading, which is important for seismic design of composite buildings. These highlight the importance of considering cyclic local buckling in the analysis and design.

\subsection{Effects of column slenderness ratio}

The numerical model developed was used to examine the important effects of the column slenderness ratio. High strength thin-walled CFST slender beam-columns with a cross-section of $700 \times 700 \mathrm{~mm}$ were considered. The depth-to-thickness ratio of the section was 70 . Column slenderness ratios $\left(L_{e} / r\right)$ of 22 and 30 were considered in the parametric study. The steel tubes were filled with high strength concrete of $70 \mathrm{MPa}$. The axial load of $4131.2 \mathrm{kN}$ was applied to the beam-column.

The cyclic load-deflection curves for high strength thin-walled CFST slender beam-columns with $L_{e} / r$ ratios of 22 and 30 are presented respectively in Figs. 10(a) and 10(b). The ultimate lateral load of thin-walled CFST slender beam-columns tends to decrease when increasing the column slenderness ratio of the beam-columns under the same axial load level. Columns with a smaller $L_{e} / r$ ratio are shown to be less ductile than the ones with a larger $L_{e} / r$ ratio. The lateral deflection at the ultimate cyclic lateral load of the beam-columns increases with increasing the column slenderness ratio. When increasing the column slenderness ratio from 22 to 30, the ultimate cyclic lateral load of the slender beam-column decreases by $28.7 \%$. 
This demonstrates that the column slenderness has a significant effect on the cyclic lateral load capacities of CFST slender beam-columns.

\subsection{Effects of depth-to-thickness ratio}

Local buckling of thin-walled rectangular CFST slender beam-columns depends on its depthto-thickness ratio $(D / t)$. The numerical model was employed to investigate the effects of $D / t$ ratio on the cyclic load-deflection curves for high strength CFST slender beam-columns with an $L_{e} / r$ ratio of 30 and subjected to a constant axial load of $4450.9 \mathrm{kN}$ and cyclically varying lateral loading. The dimensions of the composite section analyzed were $600 \times 600 \mathrm{~mm}$. The $D / t$ ratios of the column sections were calculated as 50 and 80 by changing the thickness of the steel tubes. The compressive strength of the in-filled concrete was $100 \mathrm{MPa}$.

Fig. 11 illustrates the effects of the $D / t$ ratio on the cyclic load-deflection curves for thinwalled CFST slender beam-columns. It can be seen from the figure that the ultimate cyclic lateral load and stiffness of the CFST slender beam-columns decrease with an increase in the $D / t$ ratio for the same size composite section. This is because the column section with a larger $D / t$ ratio has a lesser steel area and it may undergo local buckling which reduces the ultimate strength of the column. When the $D / t$ ratio is increased from 50 to 80 , the ultimate cyclic lateral load of the beam-column is found to decrease by $31.1 \%$. The results suggest that the cyclic lateral load capacity of a CFST slender beam-column can be significantly increased by using a smaller $D / t$ ratio for the cross-section in the design. 


\subsection{Effects of concrete compressive strengths}

The effects of concrete compressive strengths on the cyclic load-deflection responses of high strength CFST slender beam-columns with cyclic local buckling effects were studied by the numerical model. The compressive cylinder concrete strengths used in the parametric study were $60 \mathrm{MPa}$ and $100 \mathrm{MPa}$. The dimensions of the cross-section were $700 \times 800 \mathrm{~mm}$ with a $\mathrm{D} / \mathrm{t}$ ratio of 80 . The column slenderness ratio $\left(L_{e} / r\right)$ of 30 was specified. The applied axial load was $4119.5 \mathrm{kN}$.

The computed cyclic load-deflection curves for high strength rectangular CFST slender beamcolumns with different concrete compressive strengths are depicted in Fig. 12. The ultimate cyclic lateral loads of CFST slender beam-columns increase with an increase in the concrete compressive strength. Increasing the concrete compressive strength from $60 \mathrm{MPa}$ to $100 \mathrm{MPa}$ increases the ultimate cyclic lateral strength by $7.2 \%$. However, the initial flexural stiffness of the slender beam-columns has a slight increase due to the use of higher strength concrete. The results indicate that the use of high strength concrete will not lead to significant increase in the cyclic lateral load capacity and flexural stiffness.

\subsection{Effects of steel yield strengths}

Square thin-walled CFST slender beam-columns with different steel yield strengths and a cross-section of $650 \times 650 \mathrm{~mm}$ were analyzed using the numerical model. The depth-tothickness $(D / t)$ ratio of the section was 65 . The yield strengths of the steel tubes were 300 $\mathrm{MPa}$ and $690 \mathrm{MPa}$ and the corresponding tensile strengths were $430 \mathrm{MPa}$ and $790 \mathrm{MPa}$

respectively. The column slenderness ratio $(L / r)$ of 30 was used in the parametric study. The 
steel tube was filled with $60 \mathrm{MPa}$ concrete. A constant axial load of $2606.9 \mathrm{kN}$ was applied to the columns.

Fig. 13 gives the cyclic lateral load-deflection curves for CFST slender beam-columns with different steel yield strengths. It can be observed from figure that the steel yield strength does not have an effect on the initial flexural stiffness of the beam-columns. However, the ultimate cyclic lateral load of slender beam-columns is found to increase significantly with an increase in the steel yield strength. By increasing the steel yield strength from $300 \mathrm{MPa}$ to $690 \mathrm{MPa}$, the ultimate cyclic lateral load of the slender beam-column is found to increase by $91.3 \%$. This is because the moment capacity of the cantilever column is significantly increased by increasing the steel yield stress. Consequently, the use of high strength steel tubes leads to a significant increase in the cyclic lateral load capacities of CFST slender beam-columns.

\section{Conclusions}

This paper has presented a numerical model for the nonlinear inelastic analysis of high strength thin-walled rectangular CFST slender beam-columns under constant axial load and cyclically varying lateral loading. The model accounts for the important effects of progressive cyclic local buckling of steel tube walls under stress gradients by gradually redistributing the normal stresses within buckled steel tube walls. This method gives a more accurate simulation of the actual cyclic post-local buckling behavior of steel tubes than the modified stress-strain curve approach, which can not model the progressive cyclic local and post-local buckling. Moreover, geometric and material nonlinearities are taken into account in the numerical model. The comparative study shows that the numerical model developed predicts very well the cyclic load-deflection responses of thin-walled CFST slender beam-columns. 
Based on the parametric study, the following important conclusions are drawn:

(1) The cyclic local buckling considerably reduces the ultimate cyclic lateral loads and ductility of CFST slender beam-columns.

(2) Increasing the column or section slenderness ratio significantly reduces the ultimate cyclic lateral loads of CFST slender beam-columns.

(3) The use of high strength concrete does not result in a significant increase in the ultimate cyclic lateral loads of CFST slender beam-columns.

(4) The use of high strength steel tubes leads to a significant increase in the cyclic lateral load capacities of CFST slender beam-columns.

\section{References}

[1] Furlong RW. Strength of steel-encased concrete beam-columns. J Struct Eng ASCE 1997;93(5):113-24.

[2] Knowles RB, Park R. Strength of concrete-filled steel tubular columns. J Struct Div ASCE 1969;95(12):2565-87.

[3] Schneider SP. Axially loaded concrete-filled steel tubes. J Struct Eng ASCE 1998;124(10):1125-38.

[4] Sakino K, Nakahara H, Morino S, Nishiyama I. Behavior of centrally loaded concretefilled steel-tube short columns. J Struct Eng ASCE 2004;130(2):180-8.

[5] Fujimoto T, Mukai A, Nishiyama I, Sakino K. Behavior of eccentrically loaded concrete-filled steel tubular columns. J Struct Eng ASCE 2004;130(2):203-12.

[6] Ellobody E, Young B, Lam D. Behaviour of normal and high strength concrete-filled compact steel tube circular stub columns. J Constr Steel Res 2006;62(7):706-15. 
[7] Liu D. Behaviour of eccentrically loaded high-strength rectangular concrete-filled steel tubular columns. J Constr Steel Res 2006;62(8):839-46.

[8] Portolés JM, Romero ML, Bonet JL, Filippou FC. Experimental study on high strength concrete-filled circular tubular columns under eccentric loading. J Constr Steel Res 2011;67(4):623-33.

[9] Mursi M, Uy B. Behaviour and design of fabricated high strength steel columns subjected to biaxial bending part 1: experiments. Adv Steel Const 2006;2(4):286-313.

[10] Shakir-Khalil H, Zeghiche J. Experimental behaviour of concrete-filled rolled rectangular hollow-section columns. Struct Eng 1989;67(19):346-53.

[11] Vrcelj Z, Uy B. Strength of slender concrete-filled steel box columns incorporating local buckling. J Constr Steel Res 2002;58(2):275-300.

[12] Hu HT, Huang CS, Wu MH, Wu YM. Nonlinear analysis of axially loaded concretefilled tube columns with confinement effect. J Struct Eng ASCE 2003;129(10):1322-9.

[13] Varma AH, Ricles JM, Sause R, Lu LW. Seismic behavior and modeling of highstrength composite concrete-filled steel tube (CFT) beam-columns. J Constr Steel Res 2002;58(5-8):725-58.

[14] Varma AH, Ricles JM, Sause R, Lu LW. Seismic behavior and design of high-strength square concrete-filled steel tube beam columns. J Struct Eng ASCE 2004;130(2):16979.

[15] Han LH, Yang YF, Tao Z. Concrete-filled thin-walled steel SHS and RHS beamcolumns subjected to cyclic loading. Thin-Walled Structure 2003;41(9):801-33.

[16] Wu B, Zhao XY, Zhang JS. Cyclic behavior of thin-walled square steel tubular columns filled with demolished concrete lumps and fresh concrete. J Constr Steel Res 2012;77:69-81. 
[17] Gayathri V, Shanmugam NE, Choo YS. Concrete-filled tubular columns part 1-crosssection analysis. Int J Struct Stab Dyn 2004;4(4):459-78.

[18] Gayathri V, Shanmugam NE, Choo YS. Concrete-filled tubular columns part 2-column analysis. Int J Struct Stab Dyn 2004;4(4):479-95.

[19] Chung K, Chung J, Choi S. Prediction of pre- and post-peak behavior of concrete-filled square steel tube columns under cyclic loads using fiber element method. Thin-Walled Structure 2007;45(9):747-58.

[20] Zubydan AH, ElSabbagh AI. Monotonic and cyclic behavior of concrete-filled steeltube beam-columns considering local buckling effect. Thin-Walled Structure 2011;49(4): 465-481.

[21] Ge HB, Usami T. Strength of concrete-filled thin-walled steel box columns: experiment. J Struct Eng ASCE 1992;118(11):3036-54.

[22] Bridge RQ, O'Shea MD. Behaviour of thin-walled steel box sections with or without internal restraint. J Constr Steel Res 1998;47(1-2):73-91.

[23] Uy B. Strength of concrete filled steel box columns incorporating local buckling. J Struct Eng ASCE 2000;126(3):341-52.

[24] Han LH. Tests on stub columns of concrete-filled RHS sections. J Constr Steel Res 2002;58(3):353-72.

[25] Liang QQ, Uy B, Liew JYR. Nonlinear analysis of concrete-filled thin-walled steel box columns with local buckling effects. J Constr Steel Res 2006;62(6):581-91.

[26] Liang QQ. Performance-based analysis of concrete-filled steel tubular beam-columns, part I: theory and algorithms. J Constr Steel Res 2009;65(2):363-72.

[27] Liang QQ. Performance-based analysis of concrete-filled steel tubular beam-columns, part II: verification and applications. J Constr Steel Res 2009;65(2):351-62. 
[28] Liang QQ, Uy B, Liew JYR. Local buckling of steel plates in concrete-filled thinwalled steel tubular beam-columns. J Const Steel Res 2007;63(3):369-405.

[29] Patel VI, Liang QQ, Hadi MNS. High strength thin-walled rectangular concrete-filled steel tubular slender beam-columns, part I: modeling. J Constr Steel Res 2012;70:37784.

[30] Patel VI, Liang QQ, Hadi MNS. High strength thin-walled rectangular concrete-filled steel tubular slender beam-columns, part II: behavior. J Constr Steel Res 2012;70:36876.

[31] Liang QQ, Patel VI, Hadi MNS. Biaxially loaded high-strength concrete-filled steel tubular slender beam-columns, part I: multiscale simulation. J Constr Steel Res 2012;75:64-71.

[32] Mander JB, Priestley MJN, Park R. Theoretical stress-strain model for confined concrete. J Struct Eng ASCE 1988;114(8):1804-26.

[33] ACI Committee 318. ACI-318-11: Building code requirements for structural concrete and commentary. Detroit(MI):ACI;2011.

[34] Tomii M, Sakino K. Elastic-plastic behavior of concrete filled square steel tubular beam-columns. Trans Archit Inst Japn 1979;280:111-20.

[35] Shi G, Wang M, Bai Y, Wang F, Shi Y, Wang Y. Experimental and modeling study of high-strength structural steels under cyclic loading. Eng Struct 2012;37:1-13.

[36] Müller DE. A method for solving algebraic equations using an automatic computer. MTAC 1956;10:208-15. 


\section{Figures and tables}

Table 1 Ultimate cyclic lateral loads of thin-walled CFST slender beam-columns.

\begin{tabular}{|c|c|c|c|c|c|c|c|c|c|c|c|c|}
\hline Specimens & $\begin{array}{c}B \times D \times t \\
(\mathrm{~mm})\end{array}$ & $D / t$ & $\begin{array}{c}L \\
(\mathrm{~mm})\end{array}$ & $\begin{array}{c}f_{C}^{\prime} \\
(\mathrm{MPa})\end{array}$ & $\begin{array}{c}f_{s y} \\
(\mathrm{MPa})\end{array}$ & $\begin{array}{c}f_{s u} \\
(\mathrm{MPa})\end{array}$ & $\begin{array}{c}E_{S} \\
(\mathrm{GPa})\end{array}$ & $\begin{array}{c}P \\
(\mathrm{kN})\end{array}$ & $\begin{array}{c}F_{u . \exp } \\
(\mathrm{kN})\end{array}$ & $\begin{array}{c}F_{\text {u.num }} \\
(\mathrm{kN})\end{array}$ & $\frac{F_{u . n u m}}{F_{u . \exp }}$ & Ref. \\
\hline CBC-32-80-10 & $305 \times 305 \times 8.9$ & 34.29 & 1200 & 110 & 600 & 674 & 200 & 1523 & 729.55 & 696.5 & 0.95 & \multirow{8}{*}{ [14] } \\
\hline CBC-32-80-20 & $305 \times 305 \times 8.9$ & 34.29 & 1200 & 110 & 600 & 674 & 200 & 3050 & 743.18 & 698.2 & 0.94 & \\
\hline CBC-48-80-10 & $305 \times 305 \times 6.1$ & 50.00 & 1200 & 110 & 660 & 737 & 200 & 1355 & 495 & 562.7 & 1.14 & \\
\hline CBC-48-80-20 & $305 \times 305 \times 6.1$ & 50.00 & 1200 & 110 & 660 & 737 & 200 & 2715 & 545.45 & 578.4 & 1.06 & \\
\hline CBC-32-46-10 & $305 \times 305 \times 8.6$ & 35.29 & 1200 & 110 & 269 & 429 & 200 & 1255 & 429.55 & 370.1 & 0.86 & \\
\hline CBC-32-46-20 & $305 \times 305 \times 8.6$ & 35.29 & 1200 & 110 & 269 & 429 & 200 & 2515 & 470.45 & 404.8 & 0.86 & \\
\hline CBC-48-46-10 & $305 \times 305 \times 5.8$ & 52.17 & 1200 & 110 & 471 & 534 & 200 & 1178 & 388.66 & 415.7 & 1.07 & \\
\hline CBC-48-46-20 & $305 \times 305 \times 5.8$ & 52.17 & 1200 & 110 & 471 & 534 & 200 & 2270 & 415.91 & 445.0 & 1.07 & \\
\hline \multicolumn{11}{|l|}{ Mean } & 0.99 & \\
\hline \multicolumn{11}{|c|}{ Standard deviation (SD) } & 0.11 & \\
\hline \multicolumn{11}{|c|}{ Coefficient of variation (COV) } & 0.11 & \\
\hline
\end{tabular}

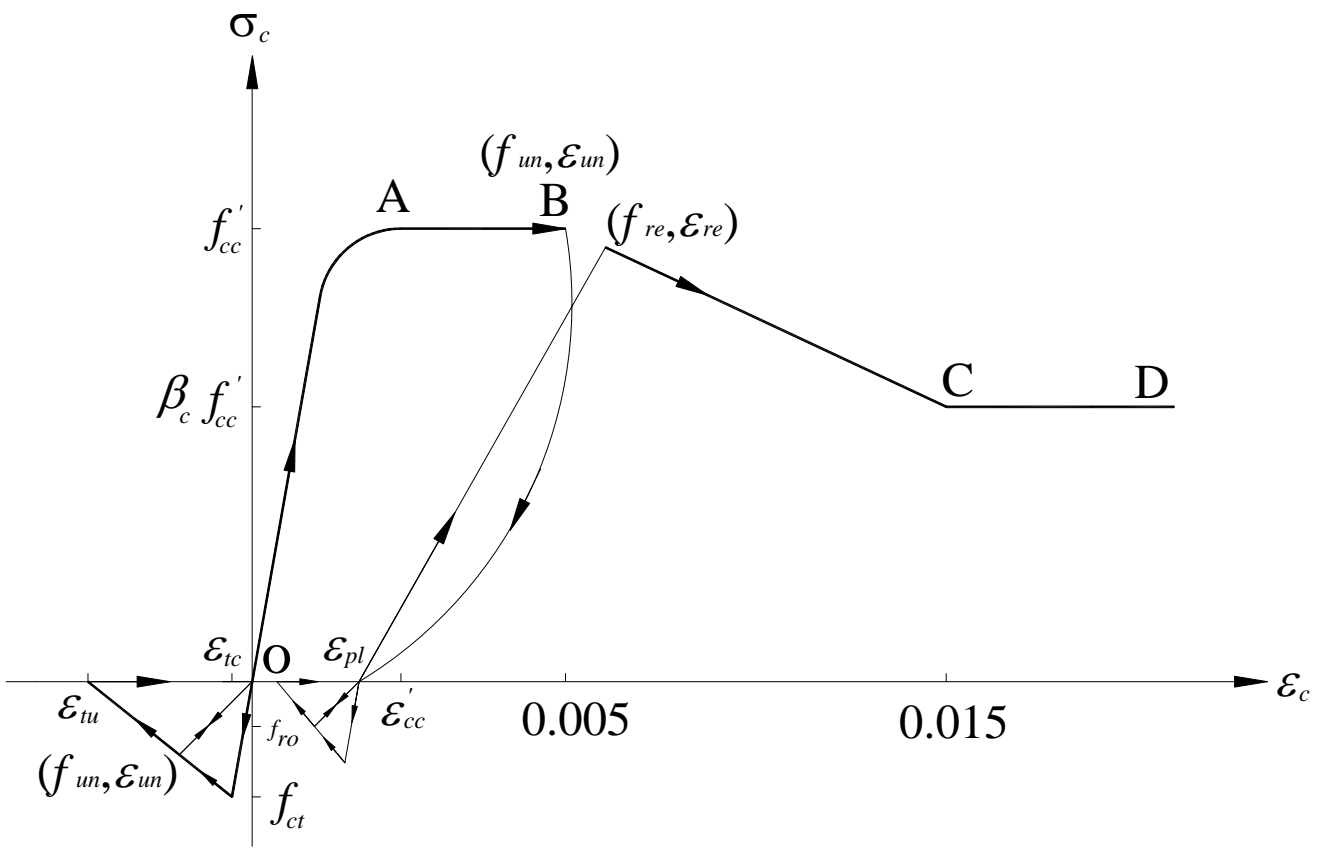

Fig. 1. Cyclic stress-strain curves for concrete in rectangular CFST columns. 


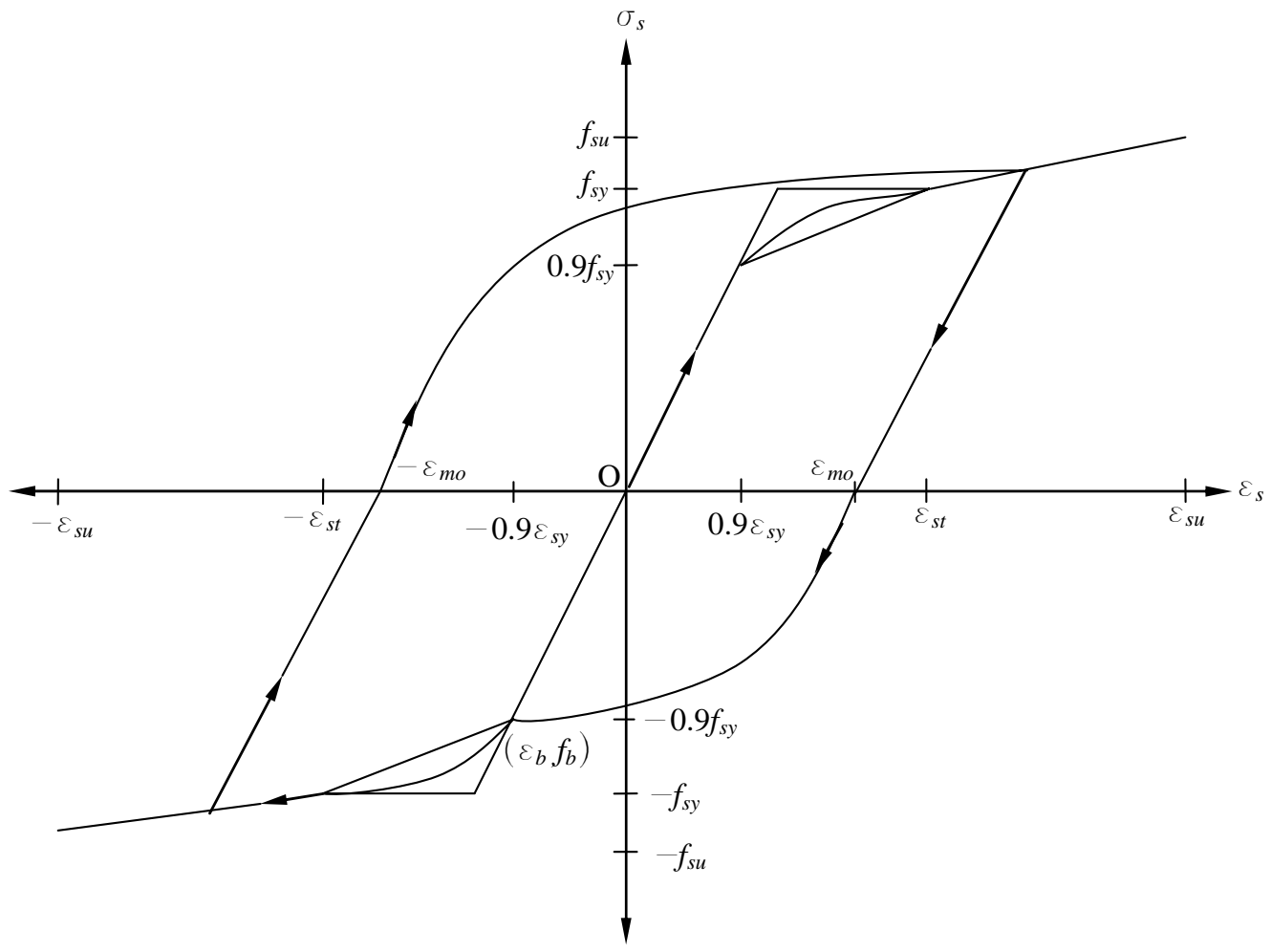

Fig. 2. Cyclic stress-strain curves for structural steels.

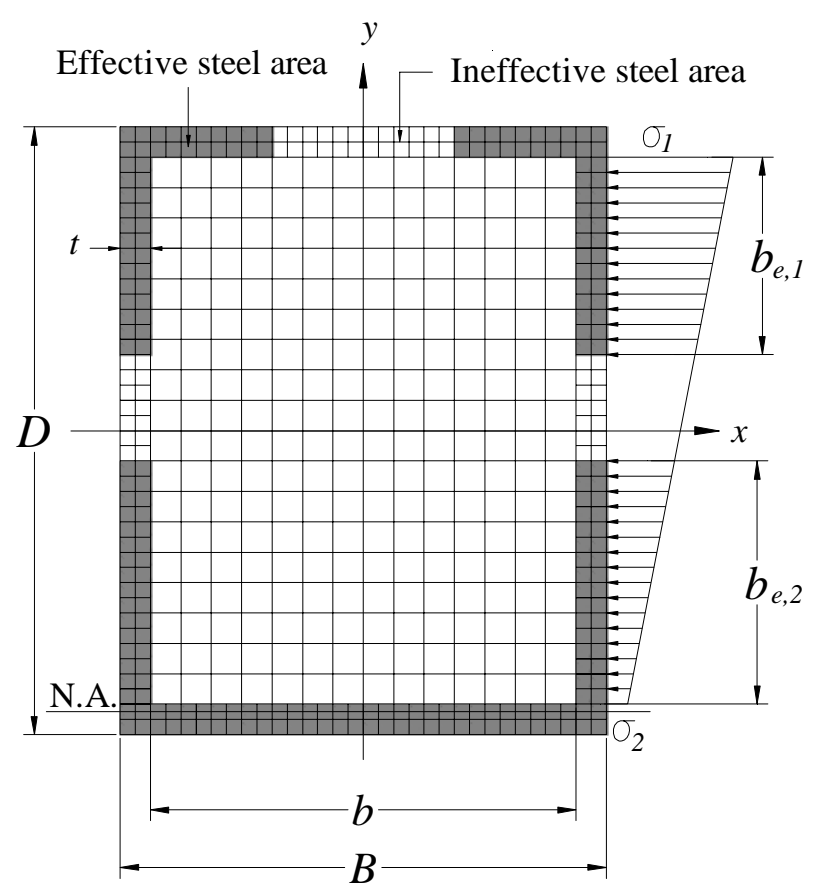

Fig. 3. Effective area of steel tubular cross-section under axial load and uniaxial bending. 


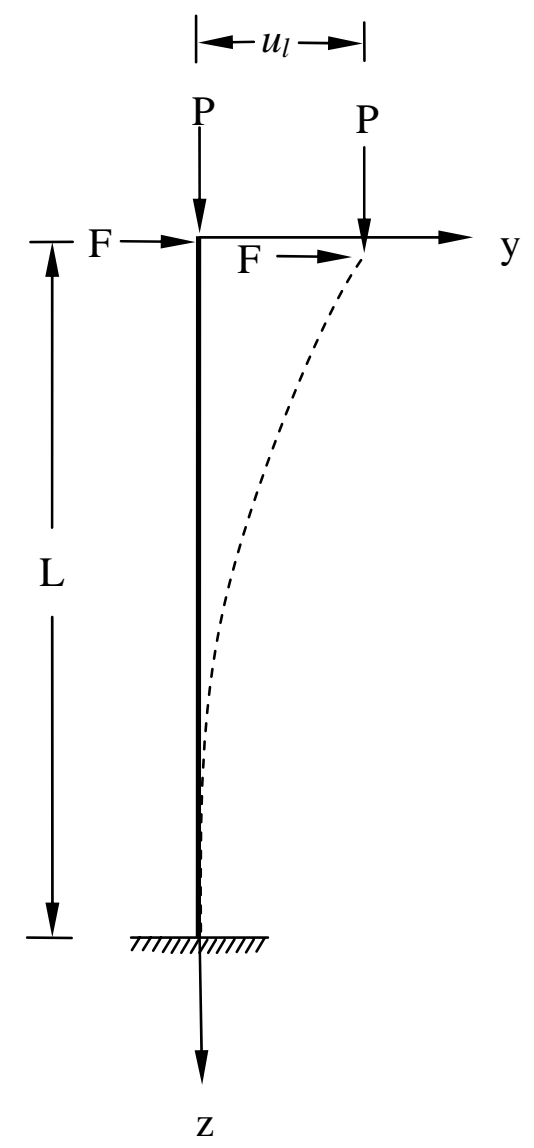

Fig. 4. Cantilever column model.

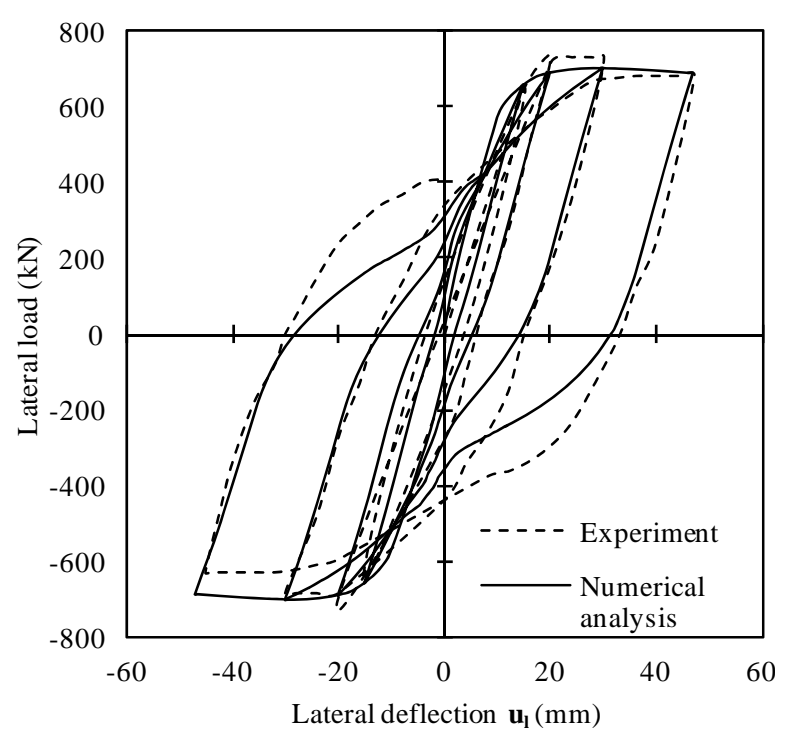

(a) Specimen CBC-32-80-1

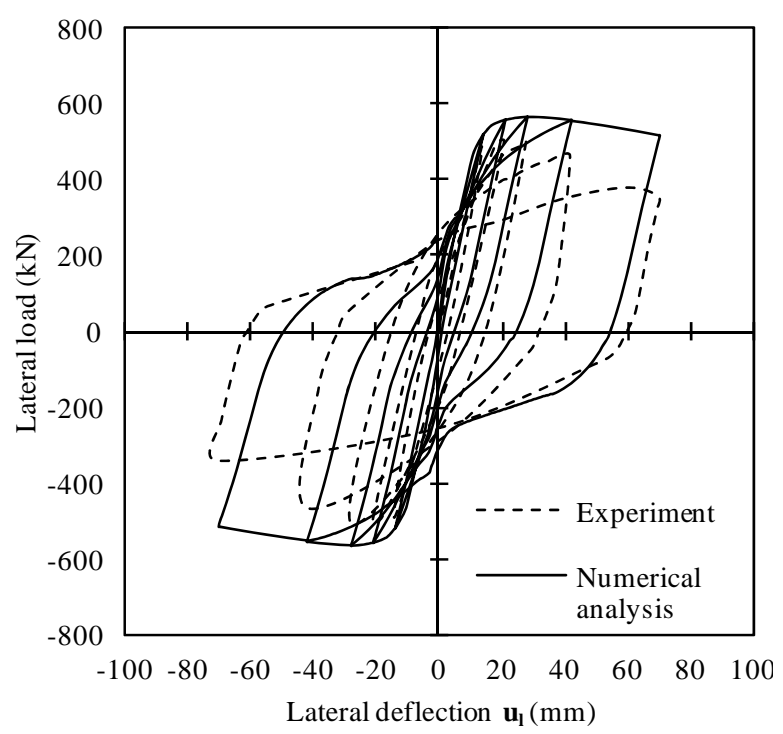

(b) Specimen CBC-48-80-10

Fig. 5. Comparison of predicted and experimental cyclic load-deflection curves for specimens CBC-32-80-10 and CBC-48-80-10. 


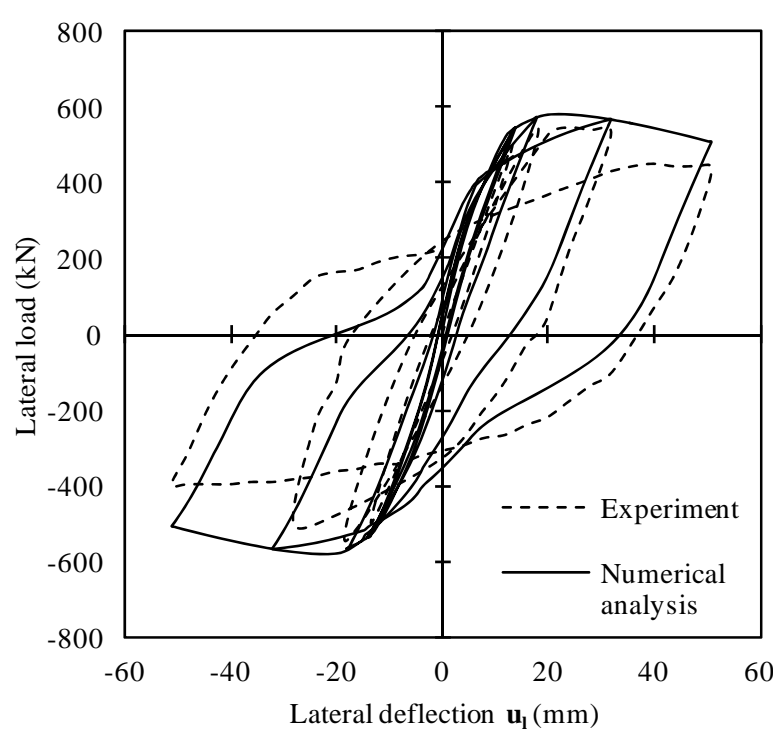

(a) Specimen CBC-48-80-20

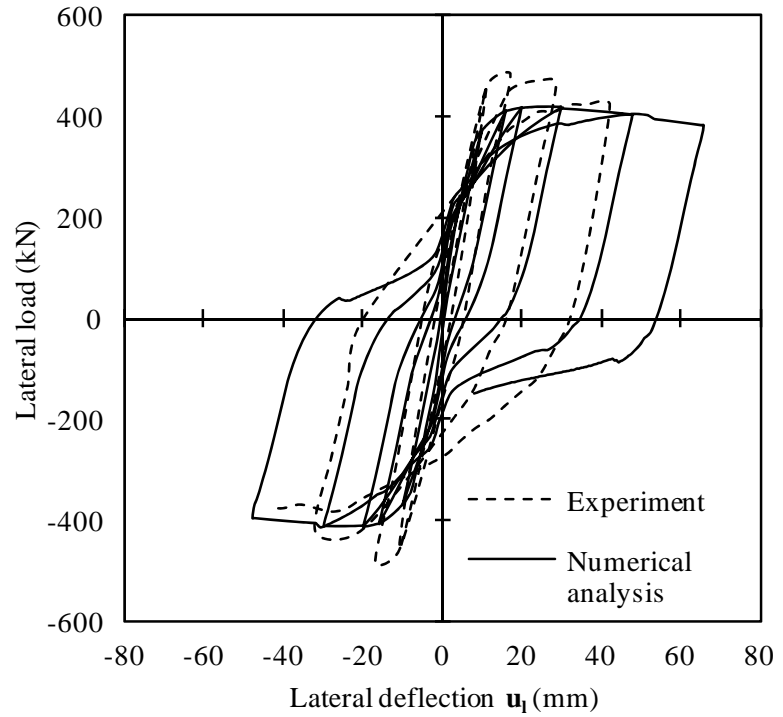

(b) Specimen CBC-32-46-20

Fig. 6. Comparison of predicted and experimental cyclic load-deflection curves for specimens CBC-48-80-20 and CBC-32-46-20.

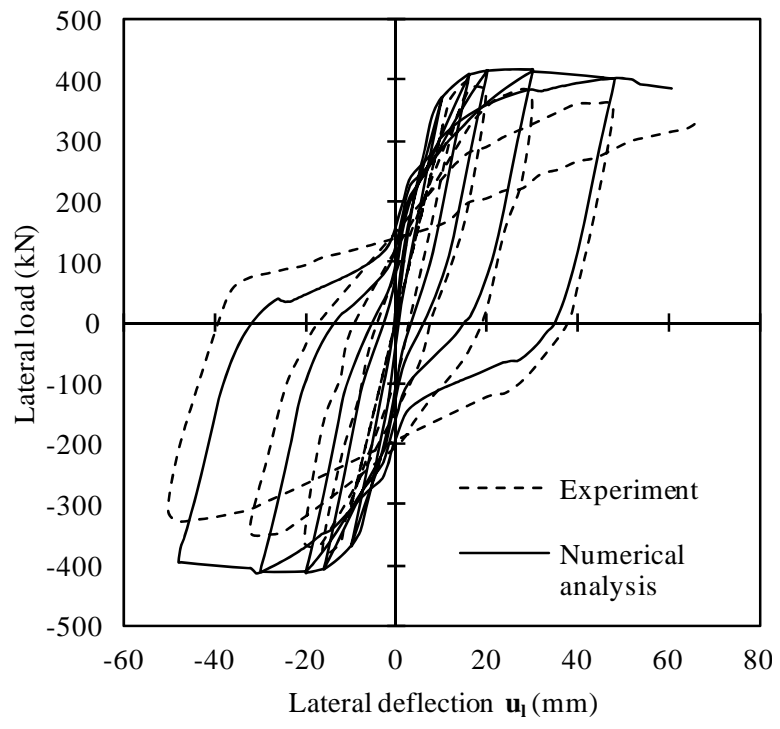

(a) Specimen CBC-48-46-10

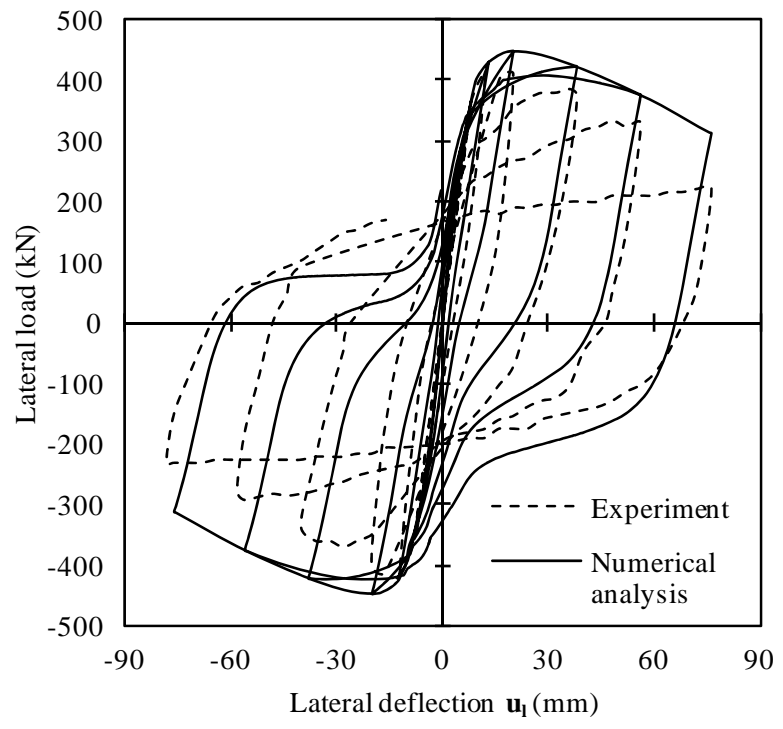

(b) Specimen CBC-48-46-20

Fig. 7. Comparison of predicted and experimental cyclic load-deflection curves for specimens CBC-48-46-10 and CBC-48-46-20. 


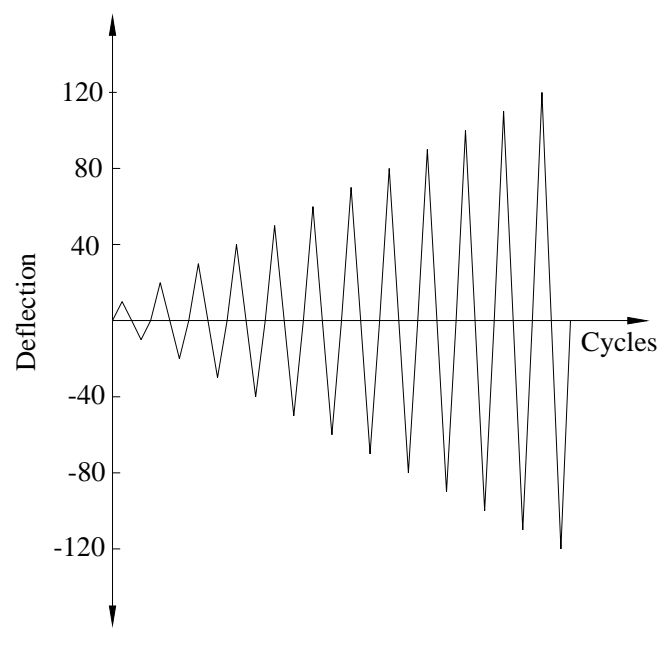

Fig. 8. Typical cyclic loading pattern

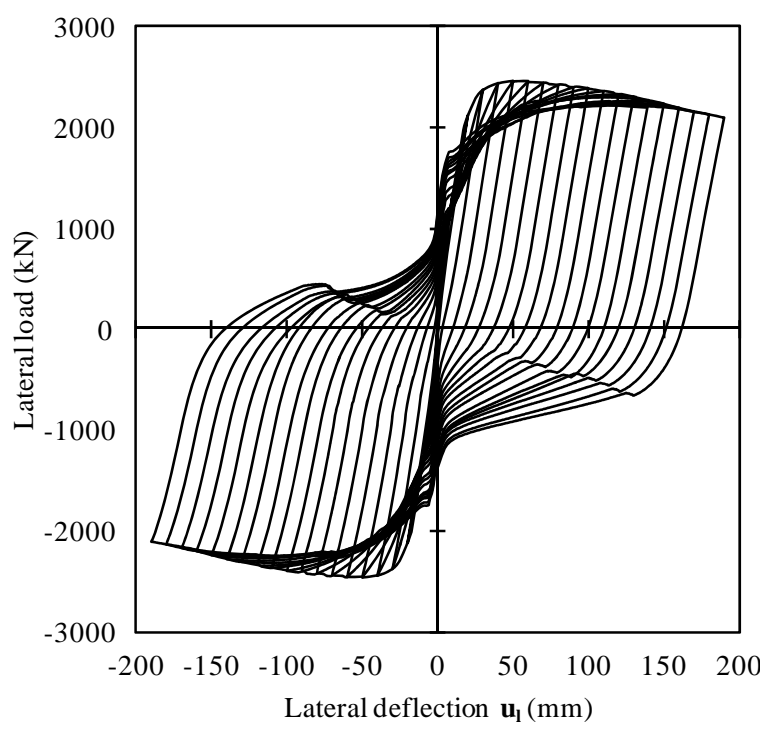

(a) Local buckling considered

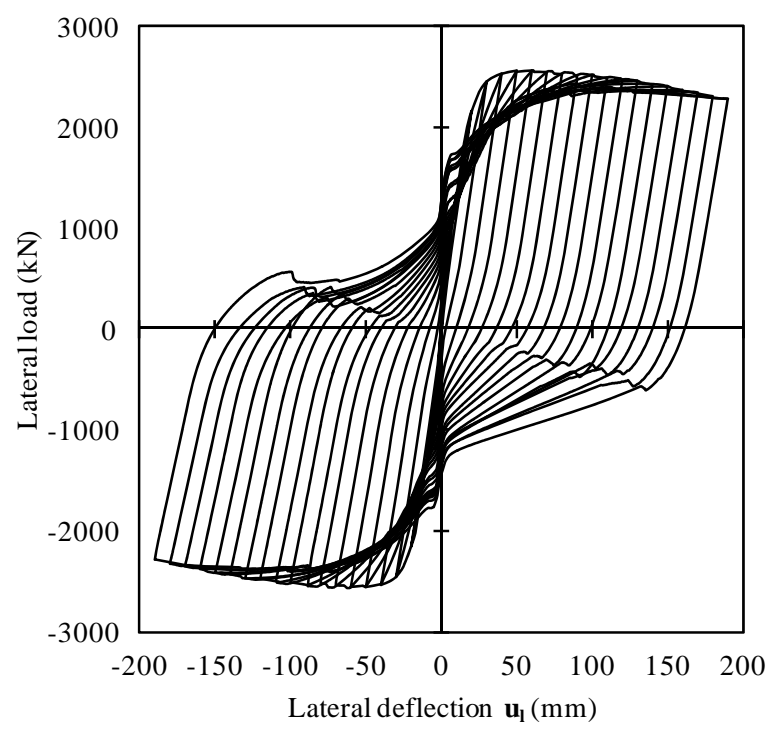

(b) Local buckling ignored

Fig. 9. Effects of local buckling on the cyclic load-deflection curves for thin-walled CFST slender beam-columns. 


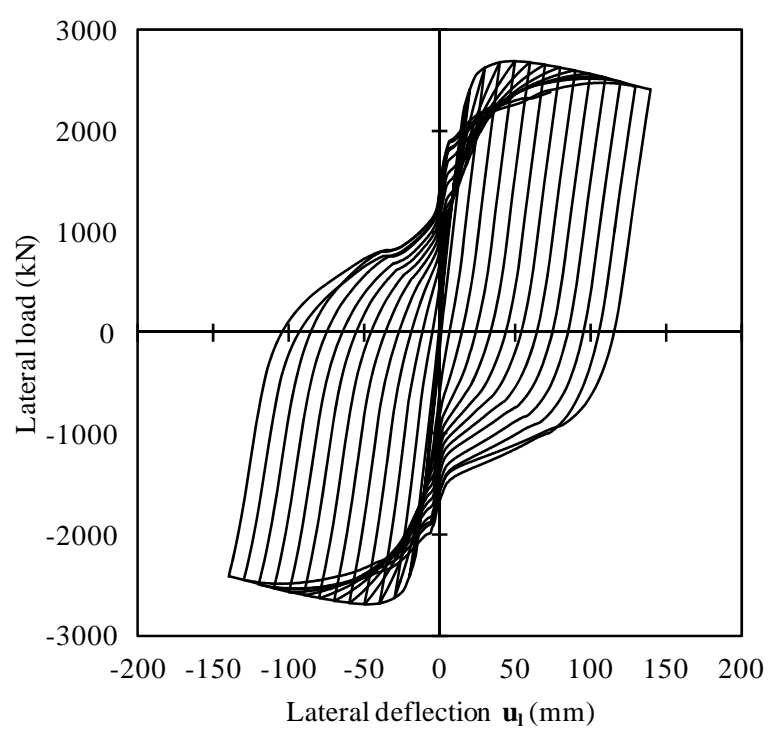

(a) $L_{e} / r=22$

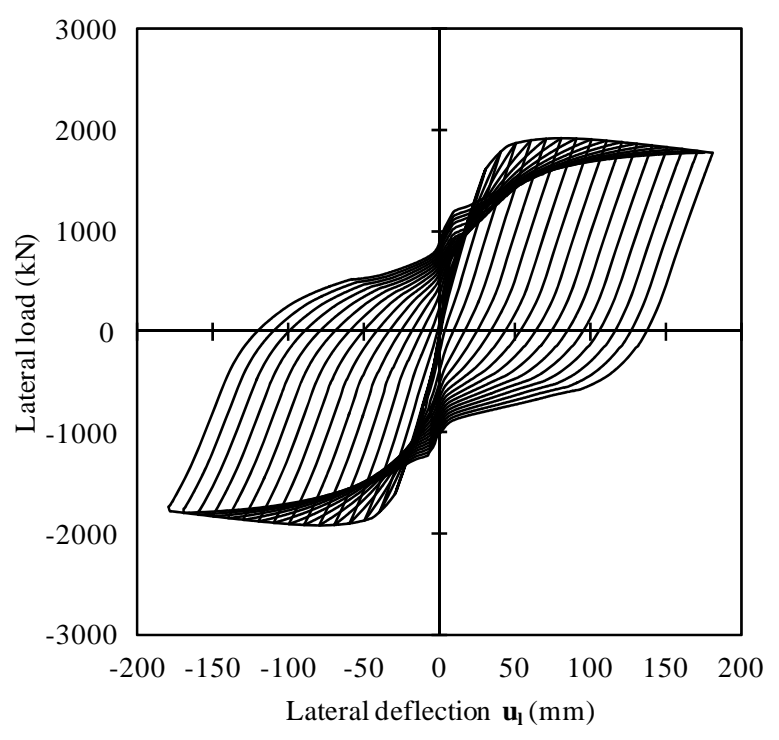

(b) $L / r=30$

Fig. 10. Effects of column slenderness ratio on the cyclic load-deflection curves for thinwalled CFST slender beam-columns.

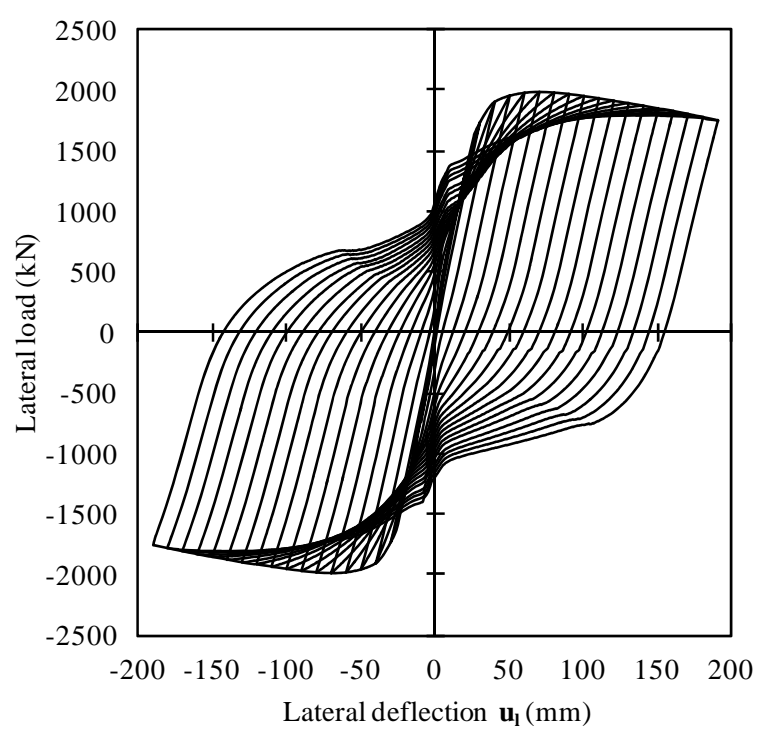

(a) $D / t=50$

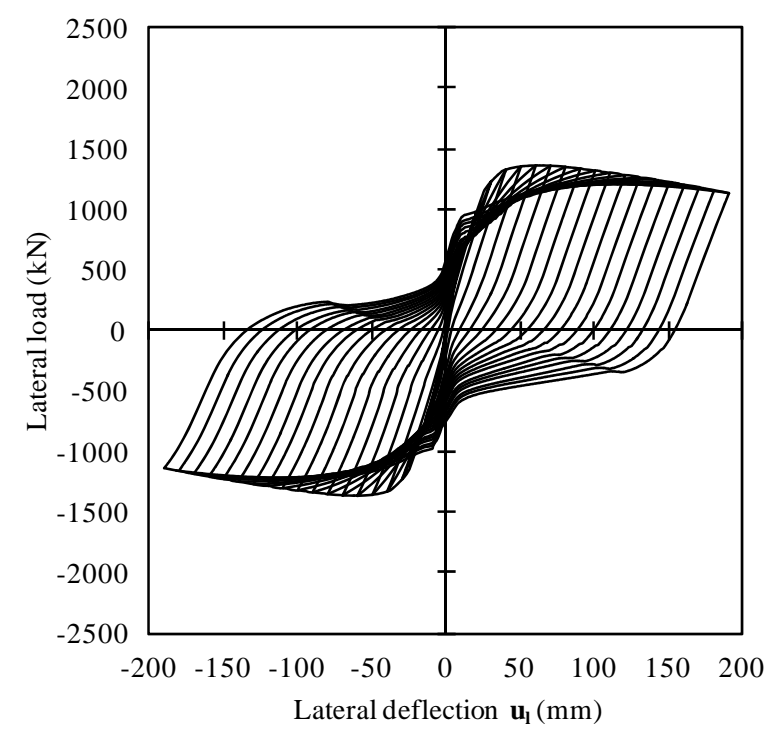

(b) $D / t=80$

Fig. 11. Effects of $D / t$ ratio on the cyclic load-deflection curves for thin-walled CFST slender beam-columns. 


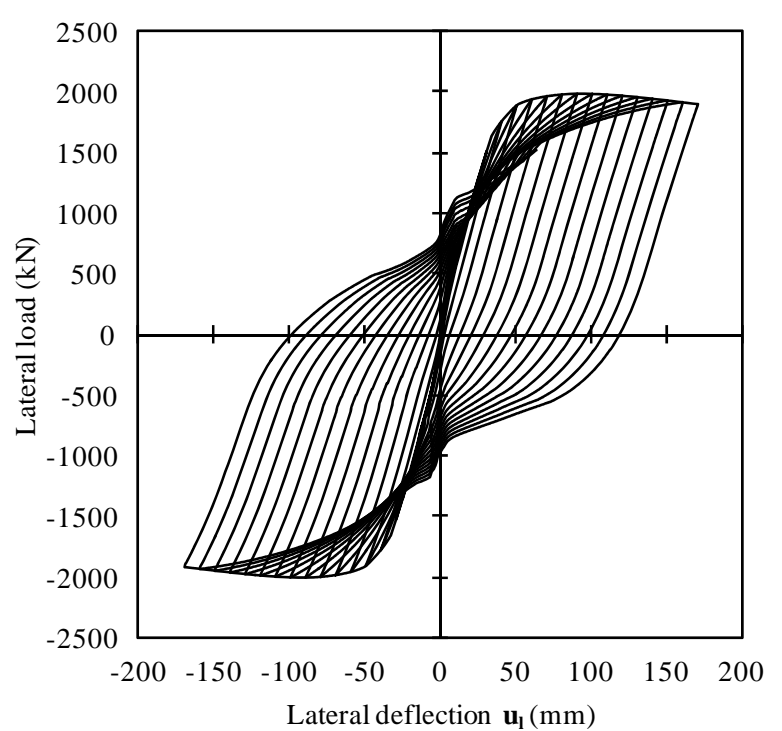

(a) $f_{c}^{\prime}=60 \mathrm{MPa}$

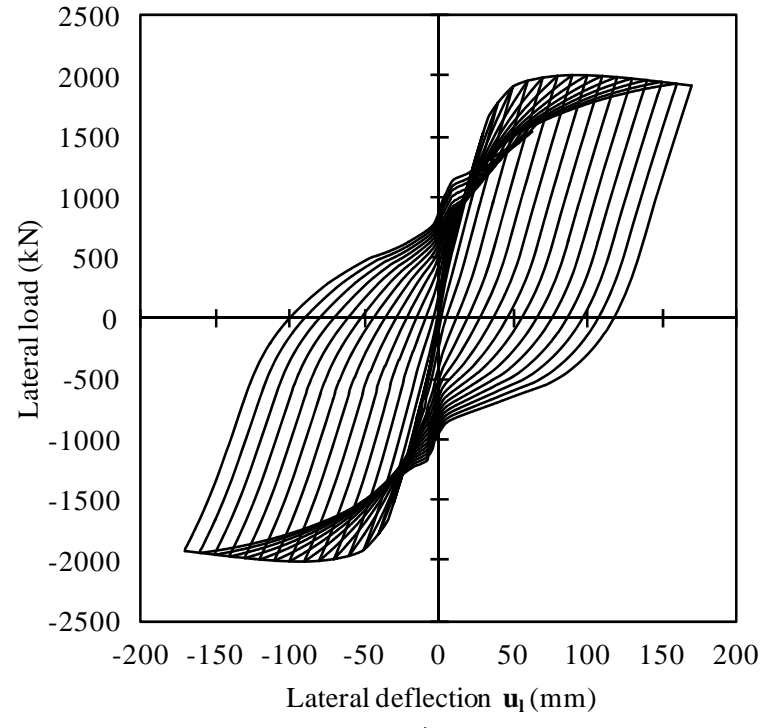

(b) $f_{c}^{\prime}=100 \mathrm{MPa}$

Fig. 12. Effects of concrete compressive strengths on the cyclic load-deflection curves for thin-walled CFST slender beam-columns.

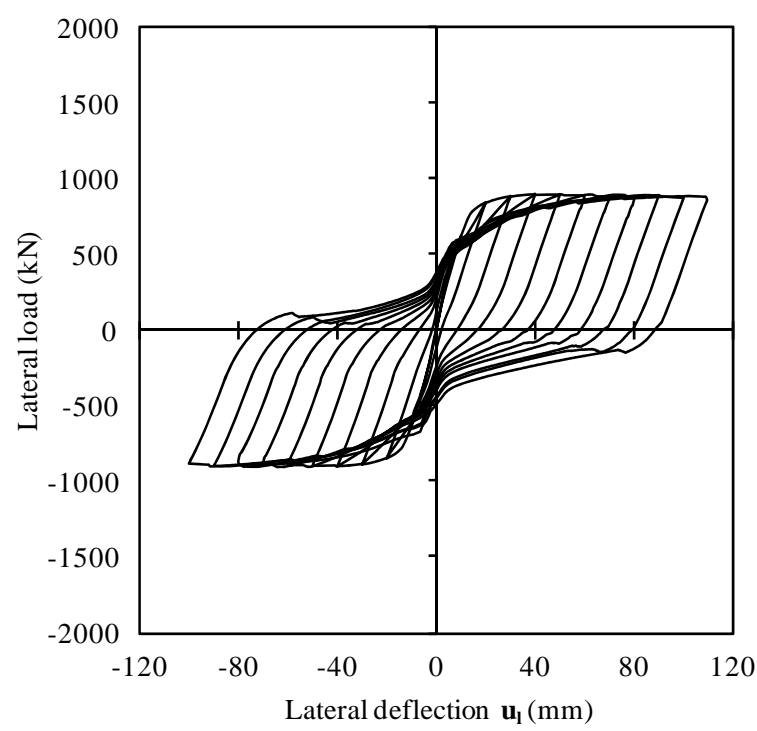

(a) $f_{s y}=300 \mathrm{MPa}$

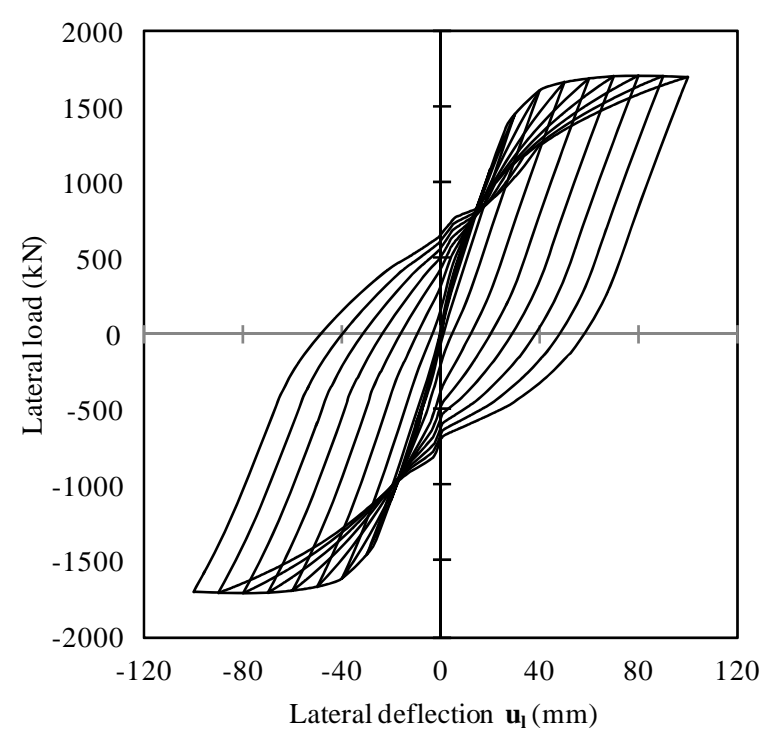

(b) $f_{s y}=690 \mathrm{MPa}$

Fig. 13. Effects of steel yield strengths on the cyclic load-deflection curves for thin-walled CFST slender beam-columns. 